
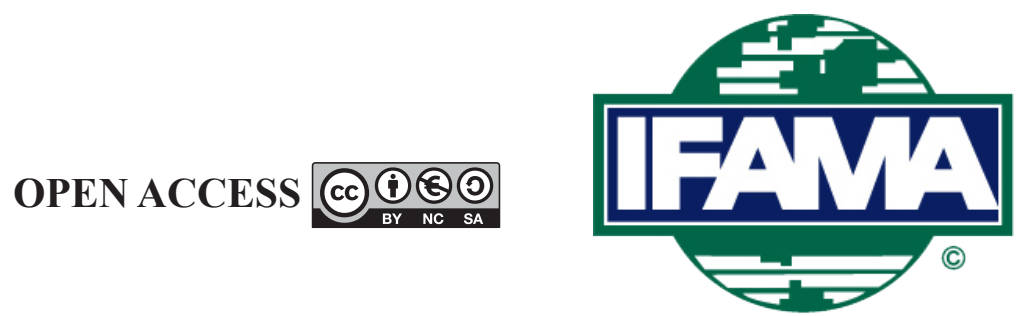

International Food and Agribusiness Management Review

Volume 23, Issue 2, 2020; DOI: 10.22434/IFAMR2019.0138

Received: 28 August 2019 / Accepted: 27 December 2019

\title{
Assessing the performance of regional soybean prices in Ghana \\ RESEARCH ARTICLE
}

\author{
Edward Martey ${ }^{\mathrm{a}}$, Nicolas Gatti ${ }^{\mathrm{b}}$ and Peter Goldsmith ${ }^{\oplus \mathrm{c}}$ \\ ${ }^{a}$ Economist, CSIR-Savanna Agricultural Research Institute, P.O. Box TL 52, Tamale, Ghana \\ ${ }^{b}$ Graduate student, ${ }^{c}$ Professor, Department of Agricultural and Consumer Economics, University of \\ Illinois at Urbana-Champaign, 318 Mumford Hall, 1301 W. Gregory, Urbana, IL 61801, USA
}

\begin{abstract}
Soybean production has been widely promoted in sub-Saharan Africa as a means of improving rural household income. Numerous studies point to poor adoption levels, low yield levels, and limited profitability among smallholder farmers. Poor performance of soybean among smallholders generates numerous hypotheses as to the root causes. One logical cause is low prices, which result from anecdotes from the field, especially among producers and policymakers. In this study, the first of its kind that we are aware of, analyzes regional soybean prices over time across six key growing and commercial regions of Ghana. We employ cointegration and multivariate vector error correction model to measure the level of international and inter-market integration and performance. The results show regional and international integration as well as Granger Causality results consistent with the local supply-demand context. Specifically, the international market Granger causes Kumasi, Bolgatanga, and Wa markets, while the Tamale and Kumasi, serve as the leading production and demand markets, respectively. The results of the study provide evidence that prices do perform well in Ghana and are not a major source of weak adoption and low levels of profitability among smallholder soybean farmers.
\end{abstract}

Keywords: soybean, cointegration, price transmission, time series, vector auto regression JEL code: Q13

\footnotetext{
${ }^{(1)}$ Corresponding author: pgoldsmi@illinois.edu
} 


\section{Introduction}

Market efficiency and integration through market liberalization leads to efficient resource allocation (Frankel and Romer, 1999; Nielsen, 2006). Specifically, market integration involves information transmission speed and details about demand and supply levels among spatially disparate locations (Negassa et al., 2003). Market information integration facilitates the efficient movement of commodities that leads to market expansion and increased competition with the long-term effect of increasing overall market system efficiency (Melitz and Trefler, 2012). Alternatively, the lack of integration involves poor information transmission, which in turn promotes imperfectly competitive markets, market concentration, the need for government intervention, and opportunities for collusion among local markets.

Price distortions and weak price transmission create market friction that result in high transaction costs for local firms and greatly limit market arbitrage (Mtumbuka et al., 2014; Portugal-Perez and Wilson, 2008; Roberts et al., 1994). Due to variability in local production, markets that are poorly integrated record higher levels of price instability (Antonaci et al., 2014).

Additionally, soybean production has been widely promoted in sub-Saharan Africa as a means of improving rural household income (Khojely et al., 2018; USDA, 2012). Numerous studies point to poor adoption levels, low yield levels, and limited profitability among smallholder farmers (Dogbe et al., 2013; Goldsmith, 2017; Lubungu et al., 2013; Tamimie et al., 2018). Poor performance of soybean among smallholders generates numerous hypotheses as to the root causes. One logical cause is low prices, which result from anecdotes from the field, especially among producers and policymakers. However, we find no previous work analyzing soybean market integration at the national level within a developing country context.

Our work helps fill a literature void about the nature of pure market effects in an emerging market, as there exists little government intervention and soybean is a relatively new commercial crop for Ghana. This study, the first of its kind in sub-Saharan Africa that we can identify, analyzes regional soybean prices over time across six key growing and commercial regions of Ghana to answer the questions as to whether prices in Ghana are too low and perform poorly. To accomplish these tasks, we conduct descriptive analyses and employ cointegration and a multivariate vector error correction model (VECM) to measure the level of international and inter-market integration and performance. The results provide farmers, industry, and policymakers factual evidence that prices do perform well in Ghana. Therefore, the design of businesses strategies and government policies should not assume market imperfections and poor price as they seek to improve the competitiveness of the agri-food complex.

\section{Literature review}

Though there are no studies on soybean markets, there have though been several analogous studies looking at regional price transmission in maize and wheat markets in sub-Saharan Africa.

Abdulai (2000) examined price relationships among three principal markets in Ghana using the threshold cointegration model. In the past, maize marketing used to be the responsibility of private commercial systems with periodic intervention by the government to help stabilize domestic price. However, the economic reforms in Ghana, such as dismantling of price and wage controls, led to complete liberalization of the maize markets and improvement in infrastructure such as the upgrade of trunk and feeder roads that link major production and consumption centers. Alderman and Shively (1996) show that liberalization and upgrading infrastructure improved trade flows among regional markets and a reduced maize price in real terms. Egyir et al. (2011) though find minimal improvement in maize price transmission and the presence of significant transaction costs across four markets in Northern Ghana and the Accra market.

Tostao and Brorsen (2005) studied the efficiency of spatial maize arbitrage in Mozambique during the postreform period. Prior to the reform, procurement, distribution, and processing of maize was the responsibility 
of subsidized government-owned companies. The system failed to ensure food security despite the subsidies. The authors identify transportation restrictions as the major challenge to spatial arbitrage in Mozambique. Using monthly retail price and monthly transportation data, the authors test whether market efficiency exists following the post reforms that allowed private entrepreneurs to engage in maize trading. Based on the empirical findings, they concluded that despite the improvement in spatial efficiency due to market liberalization, the relatively high transfer costs limited trade and potential benefits from operating a free market. Thus, market liberalization was a necessary though not sufficient condition for reducing food shortages and price volatility. Infrastructure improvements in the form of roads, barge expansion, and rail too are necessary, in combination with market liberalization, for true market reform (Tostao and Brorsen, 2005).

Negassa and Myers (2007) used an extension of the parity bound model that allows for dynamic shifts in regime probabilities. They estimate the effect of policy on spatial market efficiency in wheat and maize markets in Ethiopia. They found that wheat traders make excess profits most of the time since the price differences exceed transfer costs, while maize traders often make losses across the policy regimes tested.

Myers (2013) evaluated the effectiveness of inter-regional trade and storage in Malawi's private sector maize markets. Transportation of maize across regional markets has been the major responsibility of the private sector in ensuring efficient spatial arbitrage. However, there was little information regarding the role of the private sector affecting price transmission across regional markets, especially when there is a joint role of the private sector and the government parastatal setting price. The author, using a weekly price series and a non-linear cointegration model, establishes that long run market integration occurred but storage efficiency conditions were found to hold only in some markets.

Varela et al. (2013) conduct cointegration analysis for soybean across 25 locations in Indonesia using monthly data. The Indonesia study is analogous because it analyzes soybean markets but differs because soybean is a staple food in Indonesia, as opposed to a commercial crop, as is the case in Ghana. Additionally, Indonesian markets are both geographically and logistically distant, thus the low level of market integration. The authors place significant emphasis on 'remoteness', which is very important for our work where poor rural transportation infrastructure is a significant feature of our setting, while long distances are not. Finally, the paper indirectly discusses the role of farmer infrastructure investment as being effective for reducing the need for government policy interventions. This serves as excellent guidance as we shed light in this manuscript on the differences in pricing behavior between production and industrial utilization zones, which highlights the effects of spatial and temporal arbitrage, and the role of storage in soybean markets.

The above papers provide excellent methodological guidance for our use of co-integration analysis and a VECM. They also motivate the importance for policymakers to understand price behavior, not simply stochastically, but that developing country markets involve critical spatial and seasonal features that also contribute to economic efficiency, fairness along the agricultural supply chain, and rural economic development. Finally, the above articles essentially analyze price performance among local markets. However, soybean is a mature globally traded crop, where local markets are likely disciplined by imports of raw soy and/or processed meal and oil. Thus, our study includes analyses of Ghanaian price integration and performance compared with the international market, which are essential for informing public and private sectors decision making.

\section{Research setting}

Soybean production is a relatively new crop in Ghana and cultivated mostly by smallholder farmers under rain-fed conditions (Akramov and Malek, 2012; MiDA, 2010). The average area cultivated to soybean is less than 0.8 hectares. Current domestic supply lags behind domestic demand, by an estimated two thirds, thus requires significant imports of soybean grain, meal, and oil (Eshun et al., 2018; Gage et al., 2012). The Northern region alone contributes about $70 \%$ of national soybean area and about $77 \%$ of national production (SRID, 2012). While the Upper East, Upper West, Brong-Ahafo and Volta Regions comprise the minor soybean production areas in Ghana (SRID, 2012). Soybean production though shows growth in Ghana since 
2012 (SRID, 2015). Poultry and small-scale processing firms, as well as rising food oil demand account for the expansion of production (Gage et al., 2012). The poultry industry absorbs about $75 \%$ of the total soybean demanded annually. Most of these poultry industries and small-scale firms are located in the middle and southern belt of Ghana (Eshun et al., 2018; Gage et al., 2012; Pradhan et al., 2011). Both the post-harvest committee and the National Food Buffer Stock Company, both government agencies tasked with price and supply stabilization, have been active in maize and rice markets, but are absent from the relatively nascent soybean sector (Gage et al., 2012).

Selected regional markets cities are: (1) Wa; (2) Bolgatanga; (3) Tamale; (4) Techiman; (5) Kumasi; and (6) Accra (Figure 1). The first three markets are located in the northern part of Ghana. Techiman and Kumasi are located in the middle belt whereas the Accra location is in the southern coastal part of Ghana.

\section{Hypotheses}

The center of soybean production takes place in the Northern Region while utilization occurs in the middle Ashanti and southern greater Accra regions. Therefore, we hypothesize that:

H1: Tamale, the center of production in Ghana, serves as a central pricing point for the nation.

We consider Tamale, the regional capital of the Northern region, and the Wa, the market center for the Upper West, and Bolgatanga, the market center for the Upper East, as the reference production markets (Figure 1). While domestically produced grain flows from the north to the south, in general, the major routes are; TamaleTechiman, Tamale-Kumasi, Kumasi-Techiman, Kumasi-Accra and Techiman-Accra. Tamale-Bolgatanga, and Bolgatanga-Wa constitute the minor market routes.

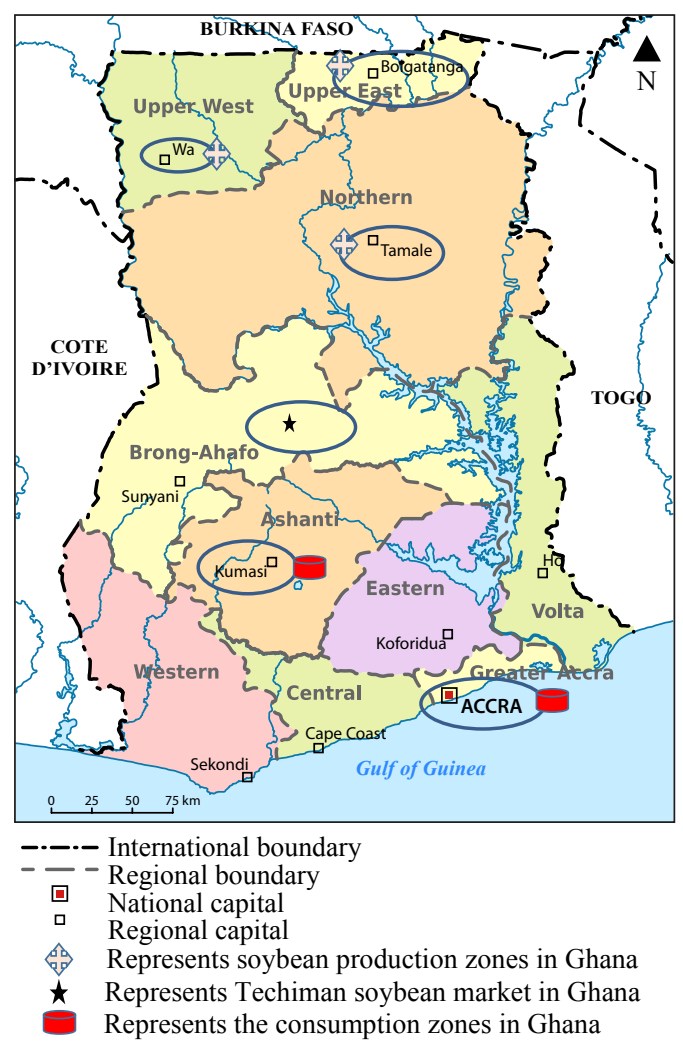

Figure 1. Administrative map of Ghana showing soybean markets. 
Tamale, the largest city in the north serves not only as the center of highest production but also contains superior logistics infrastructure. Simultaneously, Tamale and Wa supply soybean that is sold in Bolgatanga due to its proximity to Burkina Faso, that faces a 70\% $(50,000 \mathrm{mt})$ demand shortfall in its domestic supply of soybean (FAOstat, 2014), thus is a high demand-low production international market for Ghana. However, the road infrastructure between Wa and Tamale and Wa and Bolgatanga are in poor condition during our study period, which increases the cost of transport.

Therefore, we hypothesize that:

H2: Tamale and Wa serve as pricing points for Bolgatanga.

Finally, Kumasi is the most active agro-industrial area, thus is the center for commodity procurement and processing, especially soybean (Eshun et al., 2018). Kumasi serves as the largest buy-side market for soybean producers and wholesalers in Ghana. Additionally, the road networks that connect Bolgatanga, Tamale, Techiman with Kumasi are in good shape, thus facilitate trade. Therefore, we hypothesize:

H3: The Kumasi market, the agro-industrial center of the nation, also serves as a central pricing point for the nation.

Accra operates internationally importing soybean oil and meal. Ghana currently imports $40 \%$ of its soybean, $35 \%$ of its soybean meal, and $70 \%$ of its soybean oil needs, respectively. Therefore, we hypothesize that:

H4: Ghana prices are fully integrated with international prices.

\section{Methods}

\section{Data description}

This study uses weekly data of wholesale prices collected from January 2011 to August 2017 by the trade and marketing team of ACDI/VOCA, a nonprofit international economic development organization. The team collected daily soybean price per 109 kilogram 'bag', a standard trade unit in Ghana. The prices reflect an average of the daily morning and evening collections based on information from out-grower businesses and aggregators in the selected markets. The ACDI-VOCA monitoring and evaluation unit validated and cleaned the price data. We also use weekly US cash soybean prices from January 2011 to August, 2017 from Chicago Mercantile Exchange group to reflect the international price.

The local price data covers the six major regions of Ghana: (1) Upper West; (2) Upper East; (3) Northern; (4) Brong-Ahafo; (5) Ashanti; and (6) Greater Accra. In each of the regions, data collection took place in one major market center based on being the highest volume of soybean commercialization and data availability.

\section{Analytical model}

Markets are integrated when each of the prices in the different markets are non-stationary but there exists a linear combination of the price variables that is stationary which also implies a long-run equilibrium (Mafimisebi, 2012). This study analyzes the effectiveness of inter-regional trade in soybean markets using cointegration and VECM to characterize the short and long run links between local markets.

The first step of the analysis consists of analyzing the univariate time-series properties of the series using Augmented Dickey-Fuller to identify the presence of stochastic trends (unit roots) in the data. We conduct a cointegration analysis following Johansen (1988) after testing for the presence of unit roots and autocorrelation, and checking stability and normality conditions. 
We prefer the VECM model specification following Johansen (1988) methodology over instrumental variable regression by Phillips and Hansen (1990) or spectral regression by Phillips (1991) because the former method outperform the rest of the cointegration family models (Gonzalo, 1994). In the context of a system of equations that have a long-run relationship or are cointegrated, Gonzalo (1994) documents that estimating a VECM using Maximum Likelihood is the most parsimonious model that can guarantee that our estimators are unbiased and efficient. While the Autoregressive Distributed Lag Regression from Pesaran et al. $(1996,2001)$ could have been used, there is no advantage from using this method since all our series are I(1) (Shrestha and Bhatta, 2018).

Our framework identifies both the long-run co-movement between prices, as well as the short-run dynamics. We estimate the following VECM for each market price:

$$
\Delta P_{i, t}^{d}=\alpha_{0}+\alpha_{i} E C T_{t-1}+\sum_{k=1} a_{11} \Delta P_{j, t-k}^{d}+\sum_{k=1} b_{11} \Delta P_{t-k}^{i}+e_{i t}
$$

where $\Delta P_{i, t}^{d}$ is the contemporaneous first difference of domestic prices, $\Delta P_{j, t-k}^{d}$ is a vector that contains the remaining market prices, and $\Delta P_{t-k}^{i}$ is the vector containing the international soybean prices. $\Delta P_{t-k}$ refers to the lags of price differences and $e_{i t}$ are the error terms of the system of equations. $E C T_{t-1}$ reflects the deviations of the system with respect to the long-run parity. Normalizing with respect to one of the domestic prices $(i)$, the lagged error correction term is defined as a function of the remaining prices $(j)$ and the international soybean price:

$$
E C T_{t-1}=P_{i, t-1}^{d}-\text { constant }-\sum_{j=1} \beta_{j} P_{j, t-1}^{d}-\sum_{j=1} \gamma P_{t-1}^{i}
$$

From Equation 1, the vector of parameters $\alpha_{i}$ are the coefficients that show how the prices in the system respond to disequilibrium from long run parity. For example, should there be a policy shock, the sign of the error correction coefficients should be negative to guarantee that the prices return to the equilibrium.

We also analyze the direction of causality between variables within a bivariate framework using the Granger causality test. The price in one market would commonly be found to Granger-cause the price in the other market and vice versa among market pairs that are integrated of the same order (Chirwa, 2001; Nielsen, 2006). Finally, we test for long run effects if the error coefficients $\alpha$ in the $E C T$ equal zero. We reject the null hypothesis for short run causality using an F-test when $\gamma_{i}=0$ for all $d=1,2, \ldots, m$ and $\beta=0$. Mafimisebi (2012) noted that in the presence of bi-directional Granger causality, prices are said to be determined by a simultaneous feedback mechanism.

\section{Results and discussion}

\section{Descriptive analysis}

The mean prices of soybean at all locations during the study period vary between US\$ $0.38-0.63 / \mathrm{kg}$. The average price, in decreasing order, of soybean per kilogram in Accra is US\$ $0.63 / \mathrm{kg}$ followed by Kumasi (US\$ 0.47/kg), Bolgatanga (US\$ 0.44/kg), Techiman (US\$ 0.43/kg), Wa (US\$ 0.39/kg), Tamale (US\$ 0.36/ $\mathrm{kg}$ ), and Chicago (US\$ 0.33/kg) (Table 1). Thus, prices in Ghana, when measured at regional centers, should not be considered 'low' relative to international prices. That being said, the Chicago price does not reflect landed costs in Ghana. But should domestic production expand to meet demand, it appears that Ghanaian farmers will be competitive with imports, as currently local producers are able to achieve profitability at price levels below the landed price of imports. As other research has shown (Goldsmith, 2019), keys to profitability are achieving yields in excess of 1,500 kilograms per ton and efficient delivery of grain from the farms in the north to processors in the middle part of the country.

Using the coefficient of variation, we find that prices in Tamale present the largest deviation from the mean of 0.35, followed by Bolgatanga (0.30), Wa (0.28), Kumasi (0.25), Accra (0.24), Techiman (0.23), and Chicago 
Table 1. Summary statistics for weekly soybean price data.

\begin{tabular}{lllllllll}
\hline Prices & $\mathbf{N}$ & Mean & SD $^{\mathbf{1}}$ & Min. & Max. & $\mathbf{C V}^{\mathbf{1}}$ & Range & Relative range \\
\hline Accra & 80 & 0.63 & 0.15 & 0.34 & 1.01 & 0.24 & 0.68 & 1.08 \\
Bolgatanga & 80 & 0.44 & 0.13 & 0.25 & 0.8 & 0.3 & 0.55 & 1.25 \\
Kumasi & 80 & 0.47 & 0.12 & 0.24 & 0.72 & 0.25 & 0.48 & 1.02 \\
Tamale & 80 & 0.36 & 0.12 & 0.19 & 0.71 & 0.35 & 0.52 & 1.46 \\
Techiman & 80 & 0.43 & 0.1 & 0.25 & 0.71 & 0.23 & 0.46 & 1.05 \\
Wa & 80 & 0.39 & 0.11 & 0.22 & 0.65 & 0.28 & 0.43 & 1.1 \\
Chicago & 80 & 0.33 & 0.06 & 0.24 & 0.47 & 0.19 & 0.23 & 0.7 \\
\hline
\end{tabular}

${ }^{1} \mathrm{SD}=$ standard deviation; $\mathrm{CV}=$ coefficient of variation.

(0.19) (Table 1). The results imply that relatively the price of soybean in Ghana does not fluctuate widely among the analyzed markets within the period of study, and the coefficient of variation is comparable to the international market.

The CV results are consistent with the relative price range (ratio of the price range to the mean of prices). A comparison of the relative price ratios shows that Tamale at a relative range of 1.46 is significantly higher than all other markets, even the other northern markets. This reflects that high production and low utilization in the region, whereby demand is high at harvest, drive down prices in the near term. Limited storage and carryover in the country in general and the north in particular, allow for relatively high prices outside of the harvest season due to limited domestic supply, and dependence on relatively high cost of dollar-based soybean, meal, and food oil imports.

Figure 2 presents a visual representation over time of the price series under study. Most of the peak prices occurred between 2011 and 2012 while the period between 2014 and early part of 2015 witnessed significantly low soybean prices. The prices peaked at the later part of 2015 and remained low for the rest of the study period (2016 and 2017).

We dropped the Accra series because prices are significantly higher thus introduce irregularity into our analysis. Accra processes little soybean, thus imported grain travels north to the industrial center, gets

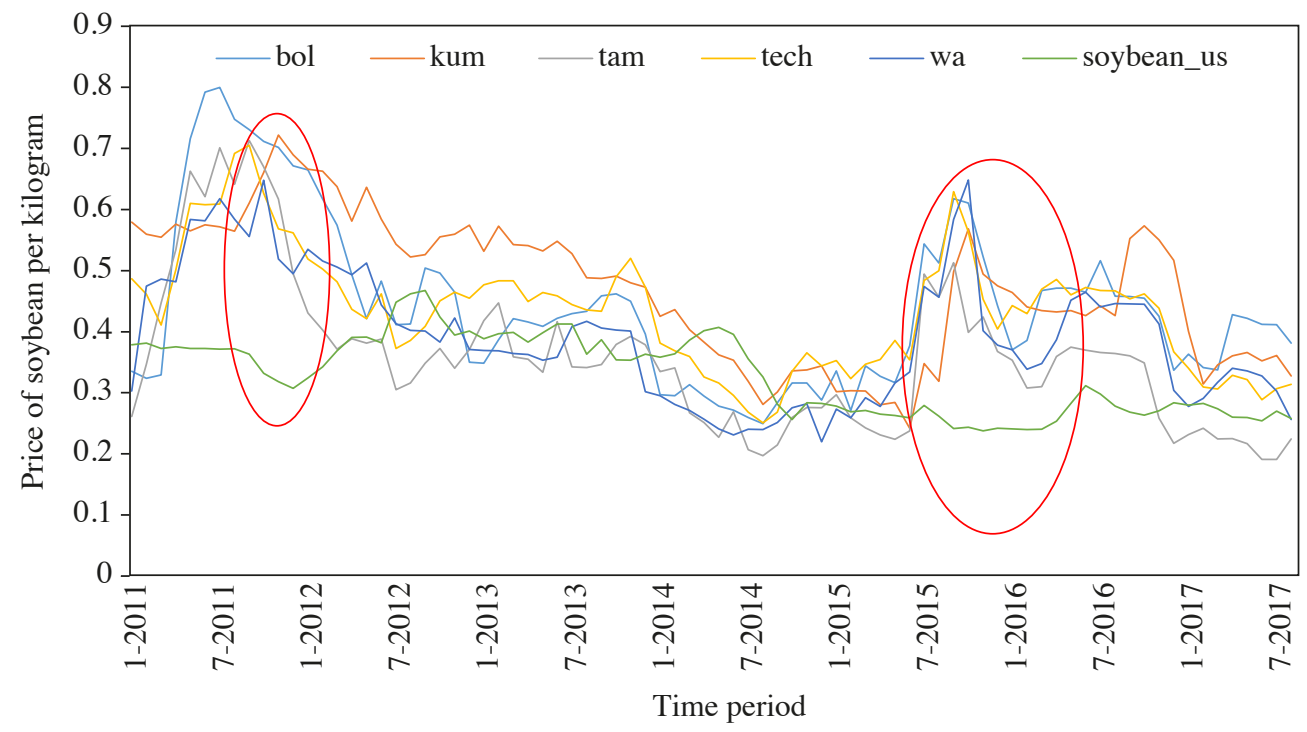

Figure 2. Domestic and international prices from 2011 to 2017. 
processed and then returns to food and the limited feed manufacturers in the south. Similarly, grain from the north must travel to the center of the country for processing prior to delivery in the south. Thus, the low processing capacity, relatively low demand, and high levels of transport currently make Accra an ancillary soybean market in the country.

The visual presentation in Figure 2 shows, as expected, the Tamale price often riding at or below the Chicago price because it serves as the nation's production region. The industrial central region reflected by Kumasi and Techiman shows opposite results with consistently higher prices relative to the Chicago price. Interestingly, Bolgatanga on the border with Burkina Faso shows relatively strong prices even though it lies only 168 kilometers away from Tamale. The relatively high price reflects the high demand and low supply conditions of Burkina Faso, the relatively weak transportation infrastructure between Bolgatanga and Tamale, and the high level of buy-side competition for Tamale's annual production between buyers in the north and central regions. Finally, the visual presentation does show two periods, pre-harvest 2011 and 2015, where Ghanaian prices separate from the international price. This reflects the relative slowness of the Ghanaian harvest that is completely unmechanized, and the poor storage and transport infrastructure that can isolate for brief periods Ghana's upland agro-industrial center.

Table 2 shows the price spreads between regional markets. The study identifies five major and two minor trade routes involving the six selected market locations that capture the bulk of Ghana's soybean trade and the associated transaction costs (transportation, search, and negotiation). All the mean price spreads were negative except the adjacent markets of Bolgatanga-Wa and Kumasi-Techiman. The Tamale and Kumasi market pair lie the farthest apart, at 383 kilometers, among the regional market pairs followed by TechimanAccra $(370 \mathrm{~km})$. Kumasi-Techiman are the closest $(127 \mathrm{~km}$.) regional market pair. As expected, the farthest market pairs experience relatively higher absolute mean price spread compared to adjacent markets. For example, in absolute terms, Techiman and Accra recorded a mean spread of US\$ 0.20/kg while the closest market pair (Kumasi-Techiman) recorded a mean price spread of US\$ 0.04/kg in absolute terms. The coefficient of variation (2.21) though indicates that these two-adjoining central agro-industrial cities have high price dispersion from the mean price spread. This departs from our expectation given that information flow across such markets should be rapid. However, the price per kilometer of distance travelled across the three key grain transport routes (Tamale-Techiman, Tamale-Kumasi, and Kumasi-Techiman) are relatively low and quite similar, US\$ -0.0003 , US\$ -0.0003 and US\$ 0.0003 respectively. We therefore can conclude efficient prices on average that reflect relatively good information flow across these key market pairs. The ratio of mean soybean price to distance in Bolgatanga-Wa market pair is the lowest (US\$ 0.0002) in absolute

Table 2. Price differences between major and minor soybean markets in Ghana.

\begin{tabular}{|c|c|c|c|c|c|c|c|c|}
\hline \multirow[t]{2}{*}{ Regional market pairs } & \multirow[t]{2}{*}{$\begin{array}{l}\text { Distance } \\
(\mathrm{km})\end{array}$} & \multirow[t]{2}{*}{$\begin{array}{l}\text { Mean }^{1} \\
\text { (US\$/kg) }\end{array}$} & \multirow[t]{2}{*}{$\mathrm{SD}^{1}$} & \multirow[t]{2}{*}{ Min. } & \multirow[t]{2}{*}{ Max. } & \multirow[t]{2}{*}{$\mathrm{CV}^{1}$} & \multicolumn{2}{|c|}{$\begin{array}{l}\text { Grain price } \\
(\$) / \mathbf{k m}\end{array}$} \\
\hline & & & & & & & Actual & $\begin{array}{l}\text { Relative to } \\
\text { average }\end{array}$ \\
\hline \multicolumn{9}{|l|}{ Major routes } \\
\hline Tamale-Techiman & 257 & -0.08 & 0.06 & -0.23 & 0.09 & -0.72 & -0.0003 & 1.17 \\
\hline Tamale-Kumasi & 383 & -0.11 & 0.1 & -0.32 & 0.15 & -0.87 & -0.0003 & 1.16 \\
\hline Kumasi-Techiman & 127 & 0.04 & 0.08 & -0.18 & 0.22 & 2.21 & 0.0003 & 1.14 \\
\hline Kumasi-Accra & 248 & -0.16 & 0.13 & -0.45 & 0.18 & -0.82 & -0.0006 & 2.53 \\
\hline Techiman-Accra & 370 & -0.2 & 0.07 & -0.52 & 0.07 & -0.66 & -0.0005 & 2.09 \\
\hline \multicolumn{9}{|l|}{ Minor routes } \\
\hline Tamale-Bolgatanga & 163 & -0.09 & 0.07 & -0.24 & 0.12 & -0.83 & -0.0005 & 2.03 \\
\hline Bolgatanga-Wa & 237 & 0.05 & 0.06 & -0.16 & 0.21 & 1.23 & 0.0002 & 0.84 \\
\hline Average & 255 & -0.08 & 0.08 & -0.3 & 0.15 & -0.06 & -0.0003 & N/A \\
\hline
\end{tabular}

${ }^{1} \mathrm{CV}=$ coefficient of variation; Mean = average price difference subtracting the second city from the first city; SD = standard deviation. 
terms relative to the other regional market pairs. The secondary demand markets of Accra (far south) and Bolgatanga (far north) present significantly higher price differences per kilometer, as expected, as they compete with buyers from the agro-industrial center of the country.

Movement of soybean is normally from the north (supply) to the south (demand). Imports though move south to north, for processing in the center of the country. Generally, it is expected that the dominant movement of soybean (north to south) leads to negative price spreads, and the results reflect such a condition. The secondary demand markets must pull grain from the high demand center and the high supply north, which indicates significant pricing power in Kumasi and Tamale, and not Accra, even in the face of imports.

According to Myers (2013), inter-regional trading activity is intrinsically uncertain, and it is more likely for periods of remarkably large returns to be counterbalance by other periods of low or negative returns. In such circumstances, it becomes more imperative to ascertain whether the average spreads over time provide a reasonable return to inter-regional trade in the long-run. The long-run equilibrium relationship between regional prices and price spread adjustment to equilibrium is highlighted in detail using the Granger Causality test. Given that markets are part of a system, and to also establish the correlation between two prices, we use the VECM and the Granger Causality test. We analyze market integration within a system to better understand the cointegration structure across the various supply and demand markets, and the causal relationships with respect to price determinants.

\section{Estimation results}

Following Johansen (1988), we confirm that all series have unit roots in levels, and then conduct a cointegration test to determine whether the series have a long-equilibrium. First, the lag length determination tests specify the number of auto and cross-regressive components in the short-run dynamics. Information criteria recommend at least one lag. The Final Prediction Error and Akaike's information criterion, the Hannan and Quinn information criterion and Schwarz's Bayesian information criterion recommend 1 lag, while the Log-Likelihood Ratio suggests 3 lags. After testing for autocorrelation, we consider including the maximum number of lags, which is three.

Results of the VECM cointegration model are shown in Table 3. Specification of the error correction model was based on the lag length criteria test. The results indicate that the model fits well and all the coefficients

Table 3. VECM model estimation. ${ }^{1}$

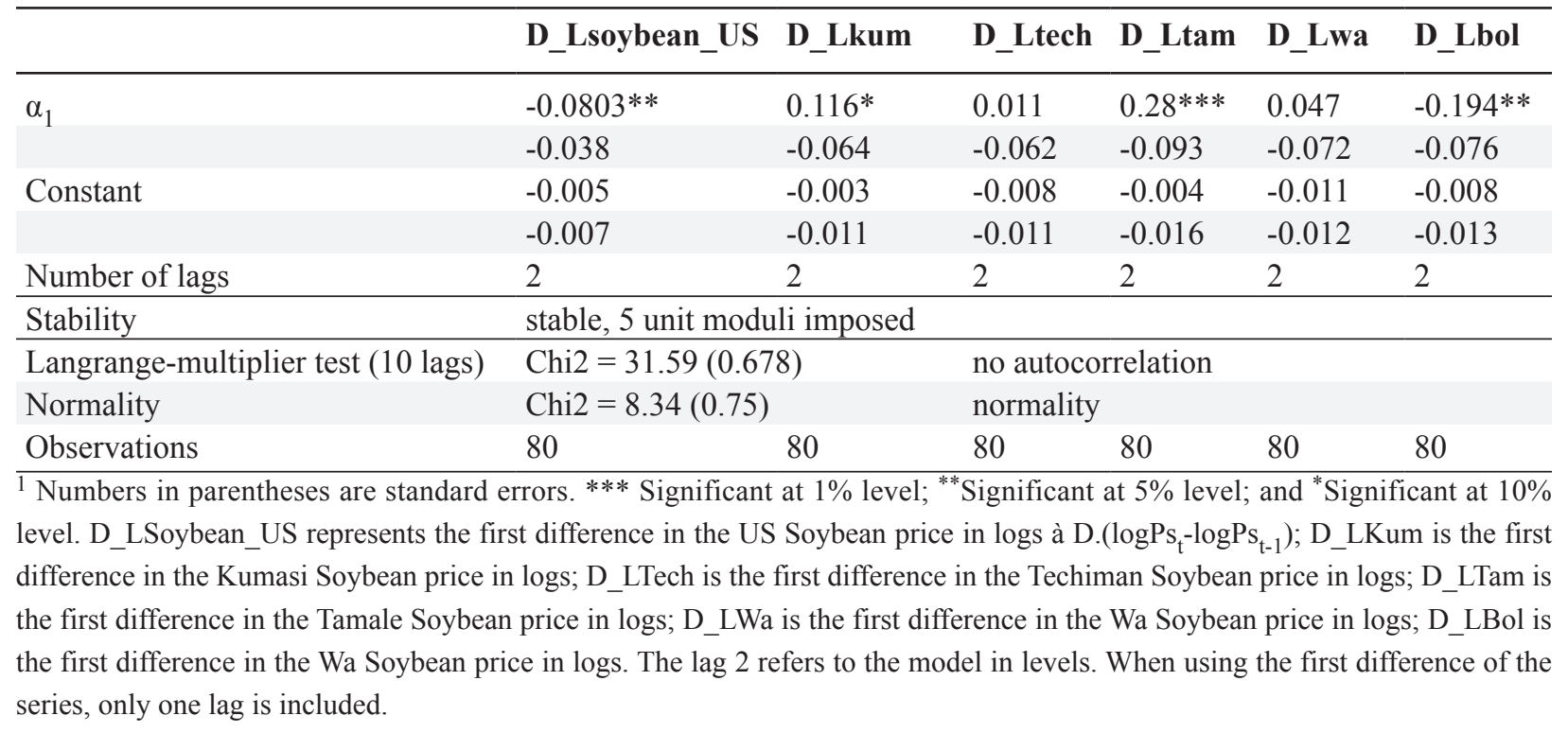


in the cointegrating equations are statistically significant, implying that local prices respond to the long run price relationship between market pairs. Johansen rank test identifies the number of cointegrating vectors characterizing the data. With five local markets prices, the test indicates at most two cointegration vectors. Hence, it can be concluded that domestic prices of soybeans are cointegrated, therefore, we proceed to estimate the VECM.

Short run coefficients $\left(\alpha_{i}\right)$ represent the speed of adjustments from deviations from the long-run parity (Table 3 ). It is worth noting that at least one coefficient in each equation of the long run adjustment is negative and statistically significant, which confirms the hypothesis of cointegration. The negative sign on at least one of the error correction coefficients guarantees the stability of the price adjustments. This means that if there is a shock and prices go up, there should be at least one price going down to ensure price stability. The results suggest an absence of serial correlation due to the insignificance of the Lagrange multiplier test at a lag length of 10. To test for normality, we analyze the consistency and efficiency of the parameter estimates. If the errors do not come from a normal distribution, but are just independently and identically distributed with zero mean and finite variance, the parameter estimates are still consistent, but they are not efficient. We reject the null hypothesis of normally distributed errors and conclude that most of the errors are not skewed but are kurtotic.

We conduct a Granger causality test to establish the response of a market to a market shock. This complements the error correction model and provides further insights into the price relationship among the market prices. Markets that play a leadership role in terms of information and transmission of prices are identified per the Granger causality test. However, the test is limited in terms of identifying the amount of information contributed by each market. More specifically, the Granger causality identifies the direction of price formation and the physical movement of the commodity to adjust for these price differential (spatial arbitrage).

Table 4 contains the results of the Granger Causality test. Following from the results, we visually depict the Table 4 causality results in Figure 3. The figure overall shows the order of transmission based on the dynamics of price changes. Specifically, the arrows reflect when a price in one market Granger-causes the price in another based, and the result is statistically significant at the 0.10 level. The market (Chicago) at the top of Figure 3 indicates the market that moves first when there is a shock.

\section{Hypothesis testing results}

H1: Tamale, the center of production in Ghana, serves as a central pricing point for the nation.

Based on the results, we confirm the null hypothesis 1 that Tamale as the center of national production serves as a central point of domestic price formation. Tamale directly affects prices in the central agro-industrial area of the country, Kumasi and Techiman. We assume that grain flows will move from low price regions (in our case Tamale) to higher price regions (i.e. Kumasi, Techiman, and Bolgatanga), then the direction of causality would be parallel, meaning that Tamale leads prices. But interestingly, Tamale shows no statistically significant $(P=0.51)$ effect over prices in the northern demand market of Bolgatanga (Table 4).

H2: Tamale and Wa serve as pricing points for Bolgatanga.

Prices in Wa influence prices in Techiman and Bolgatanga although the later (Bolgatanga) is influenced by international prices. That effect may result from the dependence of Ghana on imports combined with the limited storage capacity such that buyers quickly exhaust the domestic crop soon after harvest. The results suggest that Wa contributes to the total price formation in the Bolgatanga. Our results confirm null hypothesis 2 that among the regional markets, Wa serves as pricing points for Bolgatanga. But we cannot accept the null hypothesis with respect to Tamale, which is interesting. We surmise the weakness in affect between Tamale and Bolgatanga, which are only 163 kilometers apart, results from the acute bidding between Bolgatanga and Kumasi for Tamale's production. Kumasi's effect on prices is significant at the 0.00 level. Thus Tamale may have an indirect effect on Bolgatanga through the market in Kumasi. 
Table 4. Granger causality tests. ${ }^{1}$

\begin{tabular}{|c|c|c|c|c|c|}
\hline Equation & $\begin{array}{l}\text { Variable } \\
\text { dynamics }\end{array}$ & $\begin{array}{l}\text { Chi- } \\
\text { squared }\end{array}$ & $P$-value & Significant & Decision \\
\hline lsoybean_us & lsoybean_us & 5.93 & 0.05 & yes & lsoybean_us does Granger cause lsoybean_us \\
\hline lkum & lsoybean_us & 7.89 & 0.02 & yes & lsoybean_us does Granger cause lkum \\
\hline ltech & lsoybean_us & 2.33 & 0.31 & & lsoybean_us does not Granger cause ltech \\
\hline ltam & lsoybean_us & 1.24 & 0.54 & & lsoybean_us does not Granger cause ltam \\
\hline lbol & lsoybean_us & 4.95 & 0.08 & yes & lsoybean_us does Granger cause lbol \\
\hline lwa & lsoybean_us & 10.42 & 0.01 & yes & lsoybean_us does Granger cause lwa \\
\hline lkum & Lkum & 1.13 & 0.57 & & lkum does not Granger cause lkum \\
\hline ltech & Lkum & 8.22 & 0.02 & yes & lkum does Granger cause ltech \\
\hline ltam & Lkum & 4.13 & 0.13 & & lkum does not Granger cause ltam \\
\hline lbol & Lkum & 16.08 & 0 & yes & lkum does Granger cause lbol \\
\hline lwa & Lkum & 13.48 & 0 & yes & lkum does Granger cause lwa \\
\hline lkum & Ltech & 0.7 & 0.71 & & ltech does not Granger cause lkum \\
\hline ltech & Ltech & 0.88 & 0.64 & & ltech does not Granger cause ltech \\
\hline ltam & Ltech & 1 & 0.61 & & ltech does not Granger cause ltam \\
\hline lbol & Ltech & 0.4 & 0.82 & & ltech does not Granger cause lbol \\
\hline lwa & Ltech & 1.08 & 0.58 & & ltech does not Granger cause lwa \\
\hline lkum & Ltam & 6.37 & 0.04 & yes & ltam does Granger cause lkum \\
\hline ltech & Ltam & 5.88 & 0.05 & yes & ltam does Granger cause ltech \\
\hline ltam & Ltam & 3.57 & 0.17 & & ltam does not Granger cause ltam \\
\hline lbol & Ltam & 1.34 & 0.51 & & ltam does not Granger cause lbol \\
\hline lwa & Ltam & 2.77 & 0.25 & & ltam does not Granger cause lwa \\
\hline lkum & Lbol & 1.32 & 0.52 & & lbol does not Granger cause lkum \\
\hline ltech & Lbol & 0.87 & 0.65 & & lbol does not Granger cause ltech \\
\hline ltam & Lbol & 3.86 & 0.15 & & lbol does not Granger cause ltam \\
\hline lbol & Lbol & 2.66 & 0.26 & & lbol does not Granger cause lbol \\
\hline lwa & Lbol & 2.72 & 0.26 & & lbol does not Granger cause lkum \\
\hline lkum & lwa & 2.97 & 0.23 & & lwa does not Granger cause lkum \\
\hline ltech & lwa & 5.05 & 0.08 & yes & lwa does Granger cause ltech \\
\hline ltam & lwa & 4.26 & 0.12 & & lwa does not Granger cause ltam \\
\hline lbol & lwa & 23.59 & 0 & yes & lwa does Granger cause lwa \\
\hline lwa & lwa & 3.43 & 0.18 & & lwa does not Granger cause lwa \\
\hline
\end{tabular}

${ }^{1}$ The dynamics of each price are excluded from each of the equations to test Granger causality after VECM estimation. Highlighted areas are significant at the 0.10 level. Where: 1soybean_us reflect the Chicago cash prices, lkum reflects prices in Kumasi, ltech reflect prices in Techiman, ltam reflects prices in Tamale, lbol reflects price in Bolgatanga, and lwa reflects prices in Wa.

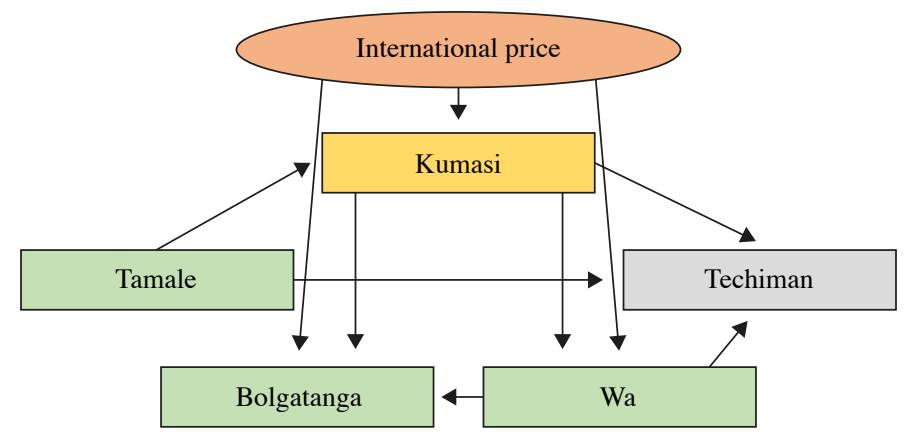

Figure 3. Summary of Granger-Causality test for regional soybean market (2011-2017). 
H3: the Kumasi market, the agro-industrial center of the nation, also serves as a central pricing point for the nation.

Our results confirm null hypothesis 3 as Kumasi affects markets in Techiman, Wa, and Bolgatanga, while being affected by international prices and the market in Tamale, Ghana's center of production.

H4: Ghana prices are fully integrated with international prices.

The results confirm the null hypothesis 4 that states that Ghanaian prices (Kumasi, Bolgatanga, Wa and Techiman) are fully integrated with international prices. Similarly, we confirm that the reverse causality does not take place, which make sense as Ghana is globally a very minor soybean producer, and whose production is principally locally utilized. International integration takes place in part because of Ghana's geography making imports possible from the Americas. Then concomitantly, Ghana imports significant levels of grain, meal, and oil to complement domestic production, which falls well short of domestic demand. Markets that have leading role in price formation are Kumasi, Bolgatanga, and Wa because international markets affect them first. Tamale and Techiman play a secondary demand role with limited processing capacity compared with the larger demand areas of Bolgatanga and Kumasi, thus it makes sense that our results show they are not influenced by any price change in the international prices. However, Tamale, as the dominant production region, affects Kumasi indicating that Tamale may add some local market information to Kumasi that is not related to international markets.

Techiman is the only market that does not influence any of the regional markets. Techiman is the last market affected by information shocks from both domestic and international prices thus is likely to be a follower or price taker.

\section{Conclusions}

Historically there has been a strong interest in grain market performance within developing country markets. The assumption was that weak logistics infrastructure, small market size, a highly fragmented farm structure, limited storage, low yields, and uneven market power across the value chain all would lead to persistently low prices and poor pricing behavior, especially vis a vis international markets. Our results do not support this assumption.

Specific to soybean, there has been significant interest to expand production for sub-Saharan Africa as a means of improving rural household income and improving malnutrition. Currently Africa supplies less than $1 \%$ of global needs, and half of Africa's production originates from one country, South Africa. So, soybean is a relatively new crop, and marketing information like we provide is essential for grain policy formulation and private sector agro-industrial investment.

The results presented in this paper, using weekly wholesale prices, show not only relatively high pricing levels, but importantly strong evidence of the existence of market integration among the regional soybean and international markets. Thus, policymakers and value chain actors should know that improper market signals are not the cause of the slow expansion of domestic supply. The causes lie elsewhere, such as poor productivity resulting from small farm size, little mechanization, incomplete technology adoption, and limited quantities of quality seed (Tamimie et al., 2018).

Specifically, we find evidence of international price influence on the prices in Bolgatanga, Kumasi, and Wa where the latter influences prices in Techiman. Interestingly, Tamale, the inland production center of the country, is disconnected from international market dynamics. However, Tamale directly affects the key demand markets of Kumasi and Techiman. In this way Tamale as the central point of production in Ghana serves as a crucial pricing point for the nation. 
Kumasi also serves as a critical pricing point for the country. Kumasi and its environs serve as home to the nation's feed, poultry, soybean processing, and food oil complex. It lies in the central industrial belt, thus functions as the central point of demand for the country and directly reflects both international and domestic supply (Tamale) market prices.

It is important to note though that our local data reflect prices at market centers, not at the farm gate. Thus, we do not take into account basis, especially actual prices received for example by a small holder producing a low volume of soybean, i.e. 200 kilograms, 50 kilometers from the market center. This is important because smaller, less productive, and more remote farmers will receive prices inferior to those we study.

In sum, the key supply and demand markets of Ghana efficiently transmit price information from outside the country and among themselves, with minimal distortions in the long run. The challenge now for the country as it seeks to substitute imports of soybean, soybean meal, and soybean oil, and spur agro-industrial development rests with improving the productivity of producers. Currently farmer profitability is low resulting from poor yields, not from low prices. This low level of profitability disincentivizes farmers to invest in soybean production and makes supply to the industrial sector unreliable. Instead Ghana's integrated market, which reflects international price, pulls significant (40\%) (Eshun et al., 2018) soybean supplies from overseas. Improved farmer productivity would allow farmers to be competitive at world prices, which would expand national supply, reduce price volatility and levels, raise rural incomes, and allow the national government to use scarce hard currency on more essential imported goods.

\section{Acknowledgements}

The authors wish to express their profound gratitude to the Feed the Future Innovation Lab for Soybean Value Chain Research (Soybean Innovation Lab (SIL)) for initiating this study. Second, we wish to thank the management of the CSIR-Savanna Agricultural Research Institute, Nyankpala for the administrative support in terms of data collection. Finally, we thank the anonymous reviewers for their valuable inputs to the manuscript. This work is supported by: (1) the Feed the Future Innovation Lab for Soybean Value Chain Research (Soybean Innovation Lab (SIL)) under the U.S. Government's global hunger and food security initiative, Feed the Future. USAID award no. AID-OAA-L-14-00001; (2) USDA NIFA Hatch/ Multistate Project ILLU-470315; (3) the Feed the Future (FTF) initiative, CGIAR Fund, award number BFS-G-11-00002, and (4) the predecessor fund the Food Security and Crisis Mitigation II grant, award number EEM-G-00-04-00013.

\section{References}

Abdulai, A. 2000. Spatial price transmission and asymmetry in the Ghanaian maize market. Journal of Development Economics 63(2): 327-349.

Akramov, K. and M. Malek. 2012. Analyzing profitability of maize, rice, and soybean production in Ghana: results of PAM and DEA analysis. Ghana Strategy Support Program. Working Paper 28. International Food Policy Research Institute, Washington, DC, USA. Available at: https://tinyurl.com/uma8x44

Alderman, H. and G. Shively. 1996. Economic reform and food prices: evidence from markets in Ghana. World Development 24(3): 521-534.

Antonaci, L., M. Demeke and A. Vezzani. 2014. The challenges of managing agricultural price and production risks in sub-Saharan Africa. ESA Working Paper No. 14-09. FAO, Rome, Italy.

Chirwa, E.W. 2001. Liberation of food marketing and market integration in Malawi. Report of African Economic Research Consortium Sponsored Research, Nairobi, Kenya.

Dogbe, W., P.M. Etwire, E. Martey, J.C. Etwire, I.I. Baba and A. Siise. 2013. Economics of soybean production: evidence from Saboba and Chereponi districts of northern region of Ghana. Journal of Agricultural Science 5(12): 38. 
Egyir, I.S., R.M. Al-Hassan and J.K. Abakah. 2011. The effect of ICT-based market information services on the performance of agricultural markets: experiences from Ghana. International Journal of ICT Research and Development in Africa 2(2): 1-13.

Eshun, J.K., O. Kwame, E. Boateng and H. Kwaku. 2018. A comprehensive study on the activities of soy processing facilities in Kumasi and its environs. University of Cape Coast, Department of Geography and Regional Planning, Cape Coast, Ghana, $41 \mathrm{pp}$.

FAOstat. 2014. Burkina Faso soybean, soybean meal, and soybean oil supply and demand balance. FAO, Rome, Italy. Available at: http://www.fao.org/faostat/en/\#data

Frankel, J.A. and D. Romer. 1999. Does trade cause growth? American Economic Review 89(3): 379-399.

Gage, D., J. Bangnikon, H. Abeka-Afari, C. Hanif, J. Addaquay, V. Antwi and A. Hale. 2012. The market for maize, rice, soy, and warehousing in northern Ghana. USAID's Enabling Agricultural Trade Project. USAID, Washington, DC, USA.

Goldsmith, P.D. 2017. The Faustian Bargain of commercial crop agriculture in Africa. Tropical Conservation Science 10: 1-4.

Goldsmith, P.D. 2019. The state of soybean Africa: soybean costs of production. Department of Agricultural and Consumer Economics, University of Illinois at Urbana-Champaign, Urbana, IL, USA.

Gonzalo, J. 1994. Five methods of estimating long run relationships. Journal of Econometrics 60: 203-233.

Hashem Pesaran, M., Y. Shin and R.J. Smith. 2001. Bounds testing approaches to the analysis of level relationships. Journal of Applied Econometrics 16(3): 289-326.

Johansen, S. 1988. Statistical analysis of cointegration vectors. Journal of Economic Dynamics and Control 12(2-3): 231-254.

Khojely, D.M., S.E. Ibrahim, E. Sapey and T. Han. 2018. History, current status, and prospects of soybean production and research in sub-Saharan Africa. The Crop Journal 6(3): 226-235.

Lubungu, M., W.J. Burke and N.J. Sitko. 2013. Analysis of the soya bean value chain in Zambia's Eastern Province. Working Paper No. 74. Indaba Agricultural Policy Research Institute, Lusaka, Zambia. Available at: http://www.iapri.org.zm/images/WorkingPapers/wp74.pdf

Mafimisebi, T.E. 2012. Spatial equilibrium, market integration and price exogeneity in dry fish marketing in Nigeria: a vector auto-regressive (VAR) approach. Journal of Economics, Finance and Administration Science 17(33): 31-37.

Melitz, M.J. and D. Trefler. 2012. Gains from trade when firms matter. The Journal of Economic Perspectives 26(2): 91-118.

Millennium Development Authority (MIDA). 2010. Investment opportunity in Ghana maize, soya and rice. Millennium Challenge Account Program, Accra, Ghana, 23 pp.

Mtumbuka, W.S., L. Mapemba, B. Maonga and M. Mwabumba. 2014. Spatial price integration among selected bean markets in Malawi: a threshold autoregressive model approach. Malawi Strategy Support Program, Working Paper 7. International Food Policy Research Institute, Washington, DC, USA.

Myers, J.R. 2013. Evaluating the effectiveness of inter-regional trade and storage in Malawi's private sector maize markets. Food Policy 41: 75-84.

Negassa, A. and R.J. Myers. 2007. Estimating policy effects on spatial market efficiency: an extension of the parity bounds model. American Journal of Agricultural Economics 89: 338-352.

Negassa, A., R. Myers and E.Z. Gabre-Madhin. 2003. Analyzing grain market efficiency in developing countries: review of existing methods and extensions to the parity bounds mode. Markets, Trade and Institutions Division Paper No. 63. International Food Policy Research Institute, Washington, DC, USA.

Nielsen, M. 2006. Market integration and causality in demand: the case study of farmed rout in Germany. $13^{\text {th }}$ Biennial Conference of International Institute of Fisheries Economics and Trade. July 11-14, 2006. Portsmouth, UK.

Pesaran, M.H., Y. Shin and R.J. Smith. 1996. Testing for the 'Existence of a Long-run Relationship'. Cambridge Working Papers in Economics No. 9622. Faculty of Economics, University of Cambridge, Cambridge, UK. 
Phillips, P.C.B. 1991. Spectral regression for co-integrated time series. In: W. Barnett, J. Powell and G. Tauchen (eds.) Nonparametric and semiparametric methods in economics and statistics. Cambridge University Press, Cambridge, UK.

Phillips, P.C.B. and B.E. Hansen. 1990. Statistical inference in instrumental variables regression with I(1) processes. Review of Economic Studies 57: 99-125.

Portugal-Perez, A. and J.S. Wilson. 2008. Trade costs in Africa: barriers and opportunities for reform. World Bank, Washington, DC, USA.

Pradhan, A., D.S. Shrestha, A. McAloon, W. Yee, M. Haas and J.A. Duffield. 2011. Energy life-cycle assessment of soybean biodiesel revisited. Transactions of the ASABE 54(3): 1031-1039.

Roberts, J.M., D.J. Stockton and C.S. Struckmeyer. 1994. Evidence on the flexibility of prices. Review of Economics and Statistics 76(1): 142-150.

Shrestha, M.B. and G.R. Bhatta. 2018. Selecting appropriate methodological framework for time series data analysis. The Journal of Finance and Data Science 4(2): 71-89. https://doi.org/10.1016/j. jfds.2017.11.001

Statistics, Research and Information Directorate of Ministry of Food and Agriculture (SRID). 2012. Production estimates. SRID, Accra, Ghana.

Statistics, Research and Information Directorate of Ministry of Food and Agriculture (SRID). 2015. Production estimates. SRID, Accra, Ghana.

Tamimie, C.A., P.D. Goldsmith and A. Winter-Nelson. 2018. Determinants of soybean adoption and performance in northern Ghana. Presented at the 2018 Agricultural \& Applied Economics Association Annual Meeting. August 5-7, 2018. Washington, DC, USA, 25 pp.

Tostao, E. and B.W. Brorson. 2005. Spatial price efficiency in Mozambique's post-reform maize markets. Agricultural Economics 33: 205-214.

United States Department of Agriculture (USDA). 2012. Evaluation of market opportunities for soybean in Tanzania. USDA, Washington, DC, USA.

Varela, G., E. Aldaz-Carroll and L. Iacovone. 2013. Determinants of market integration and price transmission in Indonesia. Journal of Southeast Asian Economies 30(1): 19-44. 


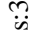

